\title{
More than eight in every nineteen inmates were living with depression at prisons of Northwest Amhara Regional State, Ethiopia, a cross sectional study design
}

\author{
Teresa Kisi Beyen ${ }^{1 *}$, Abel Fikadu Dadi ${ }^{2}$, Berihun Assefa Dachew ${ }^{2}$, Niguse Yigzaw Muluneh ${ }^{3}$
} and Telake Azale Bisetegn ${ }^{4}$

\begin{abstract}
Background: Mental health is the greatest challenges for the current and future generations. Worldwide, out of the 66 million people suffering from depression; majority (85\%) were from low and middle income countries. The prevalence was more common among the prisons population than the community. However, a worldwide consideration given to the problems is very low, particularly for prisoners.

Methods: To assess level of depression and associated factors among prisoners in prisons of Northwest Amhara Regional State, Ethiopia, Institutional based cross sectional study was employed on 727 prisoners selected by multistage random sampling from three prisons of northwest Amhara. Patient Health Questionnaire (PHQ-9) was used to assess an individuals' depression level. The reliability of the tool was checked by Cronbach's Alpha (yielding value of 0.841). Multivariable logistic regression was done to identify factors associated with depression after Hosmer and lemeshow goodness of fit test was used for model fitness.

Results: Of the total prisoners participated (649), 284 (43.8\%; 95\% Cl: 39.90, 47.67\%) had symptoms of depression. Detainees' satisfaction level about life before imprisonment, belief about their life after imprisonment, plan to commit suicide, social support and types of prisons were significantly associated with depression.

Conclusions: Depression level among detainees was found to be high. Thus, providing training to scale up satisfaction of prisoners, on how to cope up with environment just before imprisonment and release, and treating prisoners will improve the problem.
\end{abstract}

Keywords: Depression, Inmates' depression, Internees' depression, Depression in custody

\section{Background}

Worldwide, there are about 10 million people in prisons. Worldwide, prison population is being raised by around one million per decade. The majority of the world prison population were observed at low- and middle-income countries [1]. According to Penal Reform International (PRI) 2015 report, since 2004, the size of the world prison population has increased by approximately $10 \%$. Accordingly, Over the last 15 years, prison populations

\footnotetext{
* Correspondence: terek7@gmail.com

${ }^{1}$ Department of Public Health, College of Health Sciences, Arsi University, Asella, Ethiopia

Full list of author information is available at the end of the article
}

have indicated sharp rises by 150, 125 and $53 \%$ in Brazil, Colombia and Mexico respectively. US showed $16 \%$ increment in between 2001 and 2012, while also in Asia steep rises have been seen particularly in Indonesia (183\%), Vietnam (136\%), and China (modest rise). In Europe, since 2000, prison populations have fallen in Russia (particularly in Baltic States) and in some Eastern countries (e.g. Romania) even though it began to rise again after 2010. In UK and France increments have also been seen continuously. In Africa, while data are less completed, large percentages of increment have been seen in some Northern African countries like Algeria (i.e. it was 76\% between 2001 and 2013) and Morocco. 
In South Africa prison numbers was raised to maximum in 2004 and then decreased to 158,000 in 2014. The number of detainees have been risen in some, but not in all, East African countries; from 55,000 in 2000 to 93,000 in 2011 in Ethiopia [2].

Estimated 450 million people worldwide suffered from mental or behavioral disorders [3]. The problems were especially prevalent in prison populations [4]. About $11 \%$ of prisoners world-wide were suffering from common mental health problems such as depression and anxiety [5]. Mental health presents one of the greatest health problem that current and future generations will face [6]. Epidemiological studies conducted among prisoners in many countries have shown a high prevalence of psychiatric morbidity. The magnitude of severe mental disorders was five to ten times higher among prisoners compared to the general population [7]. Other studies added that mental problem was more common among the prison population [4, 8]. In European prisons, the prevalence of psychotic disorders was about $5 \%$, depressive or anxiety disorders was estimated to be $25 \%$, and substance-related disorders was approximately 40\% [9] while study among women's prison in $\mathrm{Sa}^{\sim} \mathrm{o}$ Paulo revealed that the prevalence of common mental disorders was reported as $26.6 \%$ [10]. Many of these disorders might be present before admission to prison, and might be further exacerbated by being detained $[11,12]$. However, mental disorders might also be developed during imprisonment itself as a result of prevailing conditions, possibly due to torture or other human rights violations [12].

World Health Organization (WHO) forecasted, in 2001 , that by 2020 depression will be the second leading contributor to the global burden of disease [13]. Additionally, according to the 2009 discussion paper released by World Health Organization, out of 66 million people suffering from depression; 85\% live in low and middle income countries [14]. An extensive literature review done in 24 countries revealed rates of depression of around 10 and 14\% in males and females prisoners respectively [15]. Many studies reported different levels of depression among detainees; 46.1\% among Norwegian inmates [16], 59.4\% among incarcerated women in Central Prison of Peshawar, Pakistan [17], 29\% among sentenced prisoners in Iran [18], 18\% among prisoners of England and Wales (including anxiety) [19], 10 and 12\% among men and women prisoners respectively [20], 23.3\% among prisoners of Durban, South Africa (including psychotic and anxiety disorders) [21], and 49\% among prisons and jails according to special reports of U.S. department of Justice [22]. In Kaliti Federal Prisons, Addis Ababa, Ethiopia, $61.9 \%$ of prisoners were found to have high levels of mental distress in general [23].
There were many factors in prisons that have contribution on mental health, particularly on depression including; overcrowding, various forms of violence, enforced solitude or conversely, lack of privacy, lack of meaningful activity, isolation from social networks, insecurity about future prospects (work, relationships, etc.), inadequate health services, especially mental health services in prisons, luck of social support, dissatisfaction before and after imprisonment, older ages and status of prison. The increased risk of suicide in prisons (often related to depression) was, unfortunately, one common manifestation of the cumulative effects of these factors [11, 12, 24-28].

In Ethiopia, approximately $1.7 \%$ of the national health expenditure was spent on mental health in 2004. So, in order to tackle mental health problem the Government of Ethiopia launched a National based Mental Health Strategy that can enable the government to deliver comprehensive and integrated service to mental health needs of Ethiopians [29, 30].

Majority of the population in the prison was found in the productive age category that will be returned to their community after they complete the time at jail. The government gives high attention to the prisoners to create productive mentality through implementation of different strategies that lead to the production of entrepreneur prisoners of the future country. However, the emphasis given to mental health was very low across the globe in general and for prisoners in particular. This is even more in countries with limited resource and still there is no accurate magnitude of prisoners with mental disorder who were incarcerated in Ethiopia, particularly in Northwest of Amhara Regional state and information about prisoners' health conditions is scarce. Even though health care service for mental disorder was designed in the national health policy of Ethiopia, interventions against the problem were very limited, which might be due to limited information about the problem. Thus, establishing the prevalence rates of mental disorders, particularly depression, is of great importance [31]. As a result, this study aimed to assess magnitude of depression and its attributes among prisoners detained in prisons of Northwest Amhara regional state, Ethiopia which will serve as an input for policy makers, health service planners and strategy designers.

\section{Methods}

\section{Study design and area}

Institution based cross sectional study was conducted to determine the magnitude of depression and associated factors among prison inmates found in the prisons of North West Amhara regional state, Ethiopia, from January to February 2015. The region is one of the 11 regions found in the Democratic Republic of Ethiopia. The 
region covers a total area of $20,650,420 \mathrm{Km}^{2}$ with a total population of $19,602,512$. There were 30 prisons in the region of which 10 found in the North West part of Amhara region. The numbers of prisoners found in 30 prisons were 22,590 while 7564 prison inmates were detained in the selected prisons.

\section{Sample size and sampling procedure}

Multi stage random sampling technique was used to select 727 detainees for the study. Three prisons (i.e. Bahirdar, Debre tabor and Gondar prisons) were randomly selected by lottery method from the ten prisons found in the Northwest Amhara Regional state. Then, the sample size was proportionally allocated to each prison. Then after, computer generated random number was used to select the required samples from each prisons using openEpi software. Thus, all prisoners found in the selected prisons of the Northwest Amhara regional state were the study populations. Those prisoners who were seriously ill and unable to communicate were excluded from the study. The optimum sample size (n) was computed by single population proportion formula $\left[n=\left[\left(Z_{a / 2}\right)^{2 *: P}(1-P)\right] / d^{2}\right]$ by assuming $95 \%$ confidence level, $5 \%$ margin of error (d), design effect of two, $61.9 \%$ proportion (p) among Kality prisoners [23].

\section{Data collection and data quality control}

Data were collected using structured interview aided questionnaire having seven parts (i.e. Socio-demographic characteristics, Generalized Anxiety Disorder 7-item (GAD-7) (scale ranging from zero (not at all) to three (nearly every day)) [32], Kessler Psychological Distress Scale (K10) with five level response, Patient health questioner (PHQ-9), used to assess an individual's depression scale [33, 34], social support (measured by Orientation of Social Support (OSS), scaled from 1 (very strongly disagree) to 7 (very strongly agree)) [35], Suicidal ideation and attempt, and behavioral factors, which includes history of substance use). Patient health questionnaire (PHQ-9) which contained nine questions each measuring a problem that the prisoners bothered in the last 15 days were used to measure depression with scale measurement ranging from zero (not at all) to three (nearly every day). Receiver operating characteristic (ROC) curve analysis was done by STATA version 12 software in order to determine a cut off value with high sensitivity and specificity. An individual was considered as in the state of depression if he/she has a score above seven (cut off value) which provided ROC curve area of one with $p$-value of $<0.001$. The sensitivity and specificity of the tool was found to be the highest at cut off value of seven. The internal consistency of the tools was checked by Cronbach's Alpha which yielded 0.841 values for over all internal consistency; with inter-item correlation ranging from 0.31 to 0.59 and Cronbach's alpha if items deleted ranging from 0.85 to 0.86 . The questionnaire was pre-tested before actual data collection and collected by eight B.Sc. holders after training was delivered for them on how to collect data. Then, the collected data were reviewed and checked for completeness before data entry and incomplete data were considered as none response rate.

\section{Data processing and analysis}

Data were coded, cleaned (through checking incomplete questionnaires during data collection, by doing frequency distribution and graphical presentation) and entered to Epi Info 7 and imported to STATA version 12 for further analysis. Both descriptive and inferential biostatistics procedures were undergone. Tables were used to present the data. Both bivariable and multivariable logistic regression model were used to identify factors associated with depression. Adjusted odds ratio with its 95\% Confidence interval and $p$-value was used to determine the final model. The variables were entered to the multivariable model using forward likelihood ratio variable selection method. Model fitness was tested by Hosmer and lemshow goodness of fit which provided $p$ value of 0.75 and minus log likelihood, which reduced from 889.569 to 786.198 providing chi-square of 103.371 with $p$-value of less than 0.001 .

\section{Results}

\section{Prisoners' socio demographic characteristics}

Out of total sample size, 649 (90\%) of them responded completely to the interview. The median age of the study participants was 27.75 years with inter-quartile range (IQR) of 11.7 years. Majority of the internees were males (89.8\%), 66.9\% were from urban, most of them (90\%) were orthodox followers, about half $(47.1 \%)$ of them were unmarried and $32 \%$ were grade nine to 12 complete (Table 1).

\section{Characteristic of prisoners}

The median year of stay in the penitentiary, of study participants, was 9.3 years with IQR of 3.7 years. About $22 \%$ of the inmates were sentenced for life. About half of the inmates spent most of their time on religious practices and $60 \%$ of the study participants engaged in income generating activities in the prisons. Only $10 \%$ of the study participants responded that they were satisfied with the care provided in the penitentiary (Table 2).

\section{Social support, and suicidal ideation and attempt}

Out of total internees, 293 (45.1\%) were without social support of which $9.9 \%$ were females. Nearly $17 \%$ of the total internees reported that they had idea of committing suicide since their imprisonment and $16.6 \%$ have already 
Table 1 Socio demographic characteristic of prisoners in the prisons of northwest Amhara Regional State, Ethiopia, January-February, $2015(n=649)$

\begin{tabular}{lr}
\hline Covariate & Frequency (\%) \\
\hline Mex & $583(89.8)$ \\
Female & $66(10.2)$ \\
Residence & \\
Urban & $434(66.9)$ \\
Rural & $215(33.1)$ \\
Religion & \\
Orthodox & $584(90)$ \\
Others & \\
Marital status & $65(10)$ \\
Single & \\
Married & $306(47.1)$ \\
Not live with partners & $228(35.1)$ \\
Educational status & $115(17.7)$ \\
Not read and write & \\
Read and write & $108(16.6)$ \\
1-8 grade complete & $97(14.9)$ \\
$9-12$ grade complete & $129(19.9)$ \\
Certificate and above & $206(31.9)$ \\
\hline
\end{tabular}

${ }^{\mathrm{a}}$ Muslim, Catholic and Protestant

planned to commit suicide. Additionally, $11.9 \%$ of them reported that they have made at least one attempt of suicide since imprisoned. The most reported method for the attempt of suicide were hanging (45.5\%) followed by using poison (31.2\%) while majority of them reported that they attempted suicide since they became hopeless due to the crime they have committed (39.0\%), due to economic problem (15.6\%) and felt guilty of the crime committed (18.2\%) (Table 3).

\section{Prisoners' mental health and substance abuse}

Out of the total study participants, 284 (43.8\%; 95\% CI: $39.90,47.67 \%$ ) showed signs of depression. About $14 \%$ of the prisoners reported that they had previous history of psychiatric problem and only $12.9 \%$ showed up that one of their families had experienced mental illness. About $33 \%$ of the study participants had a feeling of impossibilities to run the life they had before when released from the custody. Nearly 17 out of 20 (83.4\%) prisoners were victims of psychological distress while seven of every $20(36.1 \%)$ prisoners were at risk of anxiety. About 13 out of 20 detainees were wishing excuse of their crime and $35.3 \%$ of the detainees reported that they had no social support. Nearly, $5 \%$ of prisoners were current smokers while $18.2 \%$ of prisoners had history of Khat
Table 2 Characteristics of prisoners in the prisons of Northwest Amhara Regional State, Ethiopia, January to February, 2015 $(n=649)$

\begin{tabular}{|c|c|}
\hline Covariates & Frequency (\%) \\
\hline \multicolumn{2}{|l|}{ Type of prisoners } \\
\hline Life time prisoners & $138(21.3)$ \\
\hline Not life time prisoners & $511(78.7)$ \\
\hline \multicolumn{2}{|l|}{ Religious practice } \\
\hline Always & $308(47.5)$ \\
\hline Sometimes & $229(35.3)$ \\
\hline Never & $112(17.3)$ \\
\hline \multicolumn{2}{|c|}{ Participate in income generating activities } \\
\hline Yes & $389(59.9)$ \\
\hline No & $260(40.1)$ \\
\hline \multicolumn{2}{|c|}{ Having job before being prisoner } \\
\hline Yes & $467(72)$ \\
\hline No & $182(28)$ \\
\hline \multicolumn{2}{|c|}{ Felt happy before being prisoner } \\
\hline Yes & $567(87.4)$ \\
\hline No & $82(12.6)$ \\
\hline \multicolumn{2}{|l|}{ had friend in the prison } \\
\hline Yes & $407(62.7)$ \\
\hline No & $242(37.3)$ \\
\hline \multicolumn{2}{|c|}{ Discriminated because of imprisonment ${ }^{a}$} \\
\hline Yes & $283(43.6)$ \\
\hline No & $365(56.4)$ \\
\hline \multicolumn{2}{|c|}{ Frequency of feeling guilty of crime } \\
\hline Always & $354(54.5)$ \\
\hline Sometimes & $105(16.2)$ \\
\hline Never & $190(29.3)$ \\
\hline \multicolumn{2}{|c|}{ Perceived magnitude of mistake } \\
\hline Hard & $304(46.8)$ \\
\hline Medium & $152(23.4)$ \\
\hline Low & $193(29.7)$ \\
\hline \multicolumn{2}{|l|}{ Accepted crime committed } \\
\hline Yes & $267(41.1)$ \\
\hline No & $313(48.2)$ \\
\hline No idea & 69 (10.6) \\
\hline \multicolumn{2}{|l|}{ Crime penalty accepted } \\
\hline Yes & $30(4.6)$ \\
\hline No & $557(85.8)$ \\
\hline No idea & $62(9.6)$ \\
\hline \multicolumn{2}{|c|}{ Satisfaction with the care in the prison } \\
\hline Good Satisfaction & $65(10)$ \\
\hline Medium satisfaction & $580(89.4)$ \\
\hline Low satisfaction & $4(0.6)$ \\
\hline
\end{tabular}

aby friends, parents, and relatives 
Table 3 Social support, and suicidal ideation and attempt of prisoners in the prisons of Northwest Amhara Regional State, Ethiopia, January to February, 2015, $(n=649)$

\begin{tabular}{lc}
\hline Variables & $n(\%)$ \\
\hline Had idea of committing suicide & $110(16.9)$ \\
Yes & $539(83.1)$ \\
Planed to commit suicide & \\
Yes & $108(16.6)$ \\
No & $541(83.4)$ \\
Suicide attempted & \\
Yes & $77(11.9)$ \\
No & $572(88.1)$ \\
Methods attempted $(n=77)$ & \\
Hanging & $35(45.5)$ \\
Poison & $24(31.2)$ \\
Use sharp tools & $18(23.4)$ \\
Reasons for attempting suicide $(n=77)$ & \\
Family conflict & $6(7.8)$ \\
Economic problem & $12(15.6)$ \\
Death of family & $4(5.1)$ \\
Feel guilty of crime & $14(18.2)$ \\
Hopelessness due to crime & $30(39.0)$ \\
Lack of social support & $11(14.3)$ \\
\hline
\end{tabular}

chewing, Using Shisha, Cigarette smoking and/or Alcohol drinking.

\section{Factors associated with depression}

Bivariable logistic regression found that marital status, type of sentenced prisoners, satisfaction with day to day activity before imprisonment, discrimination due to crime, acceptance of crime penalized for, previous psychiatric problem, having family members with mental illness, thinking impossibility not to run the life they had before, social support, thinking to commit suicide, having plan to commit suicide, type of prisons and attempting suicide were significantly associated with depression. However, by Multivariable logistic regression only satisfaction with day to day activity before imprisonment, thinking impossibility not to run the life they had before, social support, type of prison and plan to commit suicide found to be significantly associated with depression (Table 4).

\section{Discussion}

This study disclosed the level of depression and associated factors among prisoners in the prisons of Northwest Amhara regional state. The study revealed that more than eight out of 19 internees were identified with depression (43.8\%). The result goes with the reports of study done among Norwegian inmates (46.1\%) [16]. This result also in line with results reported by studies conducted on different types of populations, a systematic literature review of depression among Australian women, which reported prevalence ranging from 2.6 to $43.9 \%$ [36], report's of study done in Hamadan, Iran among population over 65 years old (48.3\%) [37], and in Netherland; among older persons (48.4\%) [38]. However, It is higher than results of study in Iran among sentenced prisoners (29\%) [18], reports of Bureau of Justice Statistics among State prisoners (23\%) and jail inmates (30\%) [22], systematic review of 62 studies from 12 countries; which reported $10 \%$ among men and $12 \%$ among females [20], study conducted in Agaro town (15\%) [39], in low- to middle-income countries which ranges from 5.9 to $11.1 \%$ [28], and northern Uganda (29.2\%) [40]. On the other hand it is lower than results reported on Woman in Central Prison, Peshawar, Pakistan (59.4\%) [17], by studies done in Germany among general adults [41]. The possible explanation for the differences might be socio-demographic, socioeconomic and cultural difference between our study population and the listed studies. There were also measurement (like cut off value, and tool difference) and prison status difference which might be the other possible explanations.

The study showed that detainees who were not satisfied with their day to day life before imprisonment were $56 \%$ more likely to show signs of depression when compared to their counterpart $[\mathrm{AOR}=0.44 ; 95 \% \mathrm{CI}$ : 0.26 , 0.63]. In line with this study, many studies among different population suggested that satisfaction had strong association with depression; which stated strong positive association between low satisfaction and depression [42]. Aligned with this, respondents who thought that they would face difficulty of running life as before after being free of imprisonment were $47 \%$ more likely to develop depression when compared to their counterpart [AOR = 1.87; 95\% CI: 1.30, 2.69]. The possible reason could be as the prisoners worry about their future life they become more depressed; they are also the most stigmatized segment of the population in the society because of the crime they have done previously.

On the other way, the odds of developing depression among prisoners who had plan to commit suicide were more than four times more likely when compared with prisoners who hadn't plan to commit suicide [AOR = 4.16; 95\% CI: 2.56, 6.77]. This finding in lined with earlier reports of world health organization and American Psychiatric Association which showed that mental health disorders (specially depression) were related with more than $90 \%$ of all cases of suicide [43] and major depressive disorder alleviate the risk of suicidal ideation, 
Table 4 Factors associated with depression by bivariable and multivariable logistic regression among prisoners in the prisons of Northwest Amhara regional state, Ethiopia, January to February, $2015(n=649)$

\begin{tabular}{|c|c|c|c|c|c|}
\hline \multirow{2}{*}{$\begin{array}{l}\text { Explanatory } \\
\text { variables }\end{array}$} & \multicolumn{2}{|c|}{ Depression } & \multirow[t]{2}{*}{ COR, $95 \% \mathrm{Cl}$} & \multirow[t]{2}{*}{$\mathrm{AOR}, 95 \% \mathrm{Cl}$} & \multirow[t]{2}{*}{$P$-value } \\
\hline & Yes & No & & & \\
\hline \multicolumn{6}{|l|}{ Marital Status $^{a}$} \\
\hline Married & 88 & 140 & $0.82(0.58,1.16)$ & & \\
\hline Divorced & 24 & 28 & $1.12(0.62,2.01)$ & & \\
\hline Separated & 20 & 15 & $1.74(0.86,3.52)$ & & \\
\hline Widowed & 19 & 9 & $2.75(1.20,6.26)$ & & \\
\hline Single & 133 & 173 & 1 & & \\
\hline \multicolumn{6}{|c|}{ Type of sentenced prisoner ${ }^{a}$} \\
\hline Life time & 72 & 66 & 1 & & \\
\hline Not life time & 212 & 299 & $0.65(0.45,0.95)$ & & \\
\hline \multicolumn{6}{|c|}{$\begin{array}{l}\text { Satisfaction of day to day life } \\
\text { before imprisonment }\end{array}$} \\
\hline Yes & 232 & 335 & $0.40(0.25,0.65)$ & $0.44(0.26,0.73)$ & 0.002 \\
\hline No & 52 & 30 & 1 & & \\
\hline \multicolumn{6}{|l|}{ Discriminated ${ }^{a}$} \\
\hline Yes & 145 & 138 & $1.72(1.25,2.35)$ & & \\
\hline No & 139 & 227 & 1 & & \\
\hline \multicolumn{6}{|l|}{ Accepted crime ${ }^{a}$} \\
\hline No & 126 & 187 & 1 & & \\
\hline Yes & 113 & 154 & $1.09(0.78,1.52)$ & & \\
\hline Don't know & 45 & 24 & $2.78(1.61,4.80)$ & & \\
\hline \multicolumn{6}{|c|}{$\begin{array}{l}\text { Previous psychiatric } \\
\text { problem }^{\mathrm{a}}\end{array}$} \\
\hline Yes & 58 & 34 & $2.50(1.58,3.94)$ & & \\
\hline No & 226 & 331 & 1 & & \\
\hline \multicolumn{6}{|c|}{$\begin{array}{l}\text { Family history of mental } \\
\text { illness }^{\mathrm{a}}\end{array}$} \\
\hline Yes & 46 & 38 & $1.66(1.05,2.64)$ & & \\
\hline No & 238 & 327 & 1 & & \\
\hline \multicolumn{6}{|c|}{$\begin{array}{l}\text { Impossibilities to run life } \\
\text { as before }\end{array}$} \\
\hline Yes & 124 & 89 & $2.40(1.72,3.33)$ & $1.87(1.30,2.69)$ & 0.001 \\
\hline No & 160 & 276 & 1 & & \\
\hline \multicolumn{6}{|c|}{ Thought committing suicide ${ }^{a}$} \\
\hline Yes & 81 & 29 & $4.62(2.92,7.31)$ & & \\
\hline No & 203 & 336 & 1 & & \\
\hline \multicolumn{6}{|c|}{ Had plan to commit suicide } \\
\hline Yes & 81 & 27 & $4.99(3.13,7.98)$ & $4.16(2.56,7.77)$ & 0.000 \\
\hline No & 203 & 338 & 1 & & \\
\hline \multicolumn{6}{|c|}{$\begin{array}{l}\text { Attempted suicide since } \\
\text { imprisoned }^{\mathrm{a}}\end{array}$} \\
\hline Yes & 56 & 21 & $4.02(2.37,6.83)$ & & \\
\hline No & 228 & 344 & 1 & & \\
\hline
\end{tabular}


Table 4 Factors associated with depression by bivariable and multivariable logistic regression among prisoners in the prisons of Northwest Amhara regional state, Ethiopia, January to February, $2015(n=649)$ (Continued)

\begin{tabular}{|c|c|c|c|c|c|}
\hline \multicolumn{6}{|l|}{ Social support } \\
\hline Yes & 133 & 223 & $0.56(0.4,0.77)$ & $0.62(0.44,0.87)$ & 0.006 \\
\hline No & 151 & 142 & 1 & & \\
\hline \multicolumn{6}{|c|}{ Place of the prison } \\
\hline Gondar & 94 & 125 & $0.62(0.43,0.89)$ & $1.54(1.04,2.29)$ & 0.034 \\
\hline Debre Tabor & 60 & 130 & $0.38(0.26,0.57)$ & $2.27(1.46,3.51)$ & 0.000 \\
\hline Bahir Dar & 130 & 110 & 1 & & \\
\hline
\end{tabular}

${ }^{a}$ significant only by bivariable logistic regression

Variables that have $p$-value less than 0.05 in multivariable logistic regression were considered as significant

attempted suicide and death by completed suicide [25]. A study conducted on inmates of New South Wales, Australia also confirmed this association [44]. Another study also showed the evidence of strong positive association between depression and suicide [40]. However, prisoners who had social support were $62 \%$ less likely to be with depression's signs when compared to those who hadn't social support [AOR $=0.62$; $95 \%$ CI: $0.44,0.89$ ]. Many studies on the different population showed that depression was high among individuals who had poor social support. The possible reasons stated were lack of (poor) social support which may lead to increased psychological distress; on the other hand, good social support is vital for the prevention of anxiety, both of which have relation with depression [45]. Other studies added that loneliness has adverse consequences for mental health including depression [40, 46-49].

The study showed that prisoners in the Gondar and Debre Tabor prisons were more likely to be imitated by depression when compared to Bahir Dar prison with $[\mathrm{AOR}=1.54 ; 95 \% \mathrm{CI}: 1.04,2.29]$ and $[\mathrm{AOR}=2.27 ; 95 \%$ CI: 1.46, 3.51] respectively. This finding was strengthened by the result from Jos maximum Security Prison, Plateau State which indicated a strong association between depression and status of prison [27]. The possible explanation for this could be age distributions of the prisoners as the distribution of old ages were higher in the Gondar and Dabre Tabor prisons. Even though age is not associated to depression in our study; studies supported that depression were more likely to occur among old ages [28, 36, 40,49-55]. The other possible reason could be as Bahir Dar's prison is regional level; there may be facility difference, which might improve the satisfaction level of the prisoners.

Even though the study indicated very important factors associated with depression, the study is not free of the limitations of cross sectional study design like lack of indicating the strong cause and effect relationship. Additionally, the study is not still free of social desirability bias because subjects were systematically more likely to provide a socially acceptable response since data was collected through self report. Furthermore, the study did not collect information on the injury and trauma as they might be other factors associated with depression.

\section{Conclusion}

In conclusion, depression level among detainees in the region was significantly high. Prisoners who had satisfaction with their day to day life before being imprisoned and social support were less likely to have depression while those who had a plan to commit suicide and who thought that they will have impossibility to run life as before if released from the prison were more likely to have depression. Additionally, place of prisons also associated with depression.

\section{Recommendation}

It would have been better if the government as well as the administrators of each prison strengthen social support within each prison and support of relatives, peers, and families for the prisoners. In addition, providing training to scale up satisfaction of prisoners, on how to cop up with new environment just before imprisonment and release, on suicide reduction and treating prisons with psychological distress and depression improve depression level.

\section{Abbreviations}

AOR: Adjusted odds ratio; COR: Crude odds ratio; GAD-7: Generalized anxiety disorder 7-item; IQR: Inter-quartile range; K10: Kessler psychological distress scale; OSS: Orientation of social support; PHQ-9: Patient health questionnaire; PRI: Penal reform international; ROC: Receiver operating characteristic; WHO: World Health Organization

\section{Acknowledgements}

We are very grateful to University of Gondar for the approval of the ethical clearance and for their technical and financial support of the study. We are also indebted to Gondar, Bahir Dar and Debre Tabor prisons' administrators for the permission as well as information they provided us to undertake this study. Finally, we would like to thank all prisoners who participated in this study and for their commitment in responding honest response to our interviews.

\section{Funding}

The donor of the research was university of Gondar from its annual research grant and the research was conducted under supervision of the university. 


\section{Availability of data and materials}

As the manuscript is our original work, we have primary data collected from the study participants and tool for the collected data. We are happy to share the data and tools through communication if someone will require both data and tools.

\section{Authors' contributions}

TKB, wrote the proposal, analyzed the data, drafted the manuscript and revised subsequent drafts. AFD, wrote the proposal, participated in data collection, analyzed the data and edited the manuscript. TA, BA and NY approved the proposal with some revisions, and revised subsequent drafts of the paper. All authors read and approved the final manuscript.

\section{Competing interests}

The authors declare that they have no competing interests.

\section{Consent for publication}

Not applicable.

\section{Ethics approval and consent to participate}

Ethical clearance was obtained from institutional research ethics review board (IRB) of University of Gondar. Permission to undertake the research was obtained from Amhara region prison administration agency and respective prison offices. Written consent was obtained from each prisoner after explaining the objective of the study. To ensure confidentiality their name and other personal identifications were not registered in the format. Privacy was kept while interviewing each prisoner. It was explained to the participants that they have been selected for the study by chance and they have the right to not respond for questions that were not comfortable for them and withdrew from the interview all in all. Prison managers as well as prisoner found with a severe mental problem/depression were advised to visit health institution. Finally, the questionnaires were kept locked after data entry was completed and then discarded after two months preparation of the manuscript.

\section{Author details}

'Department of Public Health, College of Health Sciences, Arsi University, Asella, Ethiopia. ${ }^{2}$ Department of Epidemiology and Biostatistics, Institute of Public Health, College of Medicine and Heath Science, University of Gondar, Gondar, Ethiopia. ${ }^{3}$ Department of Psychiatry, School of Medicine, College of Medicine and Heath Science, University of Gondar, Gondar, Ethiopia. ${ }^{4}$ Department of Health Education and Behavioral Science, Institute of Public Health, College of Medicine and Heath Science, University of Gondar, Gondar, Ethiopia.

Received: 22 March 2016 Accepted: 27 December 2016 Published online: 19 January 2017

\section{References}

1. Walmsley R. World prison population list. 9th ed. 2011. Available from: http://www.idcr.org.uk/wp-content/uploads/2010/09/WPPL-9-22.pdf.

2. Penal Reform International. Global prison trends 2015; special focus pull-out section drugs and imprisonment. 2015.

3. World Health Organization Report. Mental health: new understanding, new hope. Geneva. 2010

4. Brinded PMJ, Simpson AIF, Laidlaw TM, Fairley N, Malcolm F. Prevalence of psychiatric disorders in New Zealand prisons: a national study. Aust N Z J Psychiatry. 2001:35:166-73.

5. World Health Organization. Background paper for trencín statement on prisons and mental health. Slovakia: WHO Publication; 2008.

6. Halliwell MED, Main L, Richardson C. In: Foundation MH, editor. The fundamental facts; the latest facts and figures on mental health. 2007. p. 7-78.

7. Falissard BL, Gasquet I, Duburc A, de BC. Prevalence of mental disorders in French prisons for men. BMC Psychiatry. 2006;6:33.

8. Bland RC, Newman SC, Thompson AH, Dyck RJ. Psychiatric disorders in the population and in prisoners. Int J Law Psychiatry. 1998;21:273-9.

9. Blaauw ERR, Kerkhof A. Mental disorders in European prison systems. Arrangements for mentally disordered prisoners in the prison systems of 13 European countries. Int J Law Psychiatry. 2000;23:649-63.
10. Moraes PACD, Dalgalarrondo P. Mulheres encarcerated dasem São Paulo: sau'de mental e religios idade. J Bras Psiquiatr. 2006:55:50-6.

11. Brugha T. Psychosis in the community and in prisons: a report from the British National Survey of psychiatric morbidity. Am J Psychiatr. 1995;162: 774-80

12. Holley HL, Arboleda-Flórez J, Love E. Lifetime prevalence of prior suicide attempts in a remanded population and relationship to current mental illness. Int J Offender Ther Comp Criminol. 1995;39(3):190-209.

13. World Health Organization. The World Health Organization report on mental health: new understanding. New hope. Geneva; 2001.

14. World Health Organization. ECOSOC meeting addressing noncommunicable diseases and mental health: major challenges to sustainable development in the 21st century. World Health Organization; 2009. p. 1-32.

15. Fazel S, Seewald K. Severe mental illness in 33588 prisoners worldwide: systematic review and meta-regression analysis. Br J Psychiatry. 2012;200: 364-73.

16. Værøy H. Depression, anxiety, and history of substance abuse among Norwegian inmates in preventive detention: reasons to worry? BMC Psychiatry. 2011;11(40):1-7.

17. Khan TM, Hussain H, Khan G, Khan A, Badshah A, Sarwar R. Incidence of depression among incarcerated woman in central prison, Peshawar, Pakistan. Eur J Gen Med. 2012;9(1):33-8.

18. Assadi SM, Noroozian M, Pakravannejad M, Yahyazadeh O, Aghayan S, Shariat SV, et al. Psychiatric morbidity among sentenced prisoners: prevalence study in Iran. Br J Psychiatry. 2006;188:159-64.

19. Cunniffe C, Kerckhove RVd, Williams K, Hopkins K. Estimating the prevalence of disability amongst prisoners: results from the Surveying Prisoner Crime Reduction (SPCR) survey. Ministry of Justice; 2012. p. 1-8.

20. Fazel S, Danesh J. Serious mental disorder in 23000 prisoners: a systematic review of 62 surveys. Lancet. 2002;359:545-50.

21. Naidoo S, Mkize DL. Prevalence of mental disorders in a prison population in Durban, South Africa. Afr J Psychiatry. 2012;13:30-5.

22. James DJ, Glaze LE. Mental health problems of prison and jail inmates. In: US Department of Justice, editor. Bureau of Justice Statistics; 2006.

23. Asgedom A. Prevalence of mental distress among federal prisoners in Ethiopia. Addis Ababa: Department of Psychiatry, Addis Ababa University; 2008

24. Baillargeon J, Binswanger I, Penn J, Williams B, Murray O. Psychiatric disorders and repeat incarcerations: the revolving prison door. Am J Psychiatry. 2009;166:103-9.

25. American Psychiatric Association. Diagnostic and statistical manual of mental disorders. 4th ed. Washington: American Psychiatric Association; 1994

26. Ahmad A, Mazlan NH. Stress and depression: a comparison study between men and women inmates in Peninsular Malaysia. International Journal of Humanities and Social Science. 2014;4(2):153-60.

27. Armiya'u AY, Obembe A, Audu MD, Afolaranmi TO. Prevalence of psychiatric morbidity among inmates in Jos maximum security prison. Open Journal of Psychiatry. 2013;3:12-7.

28. Bromet E, Andrade LH, Hwang I, Sampson NA, Alonso J, Girolamo GD, et al. Cross-national epidemiology of DSM-IV major depressive episode. BMC Medicine. 2011;9(90):1-16.

29. Ministry of Health of Ethiopia. A report of the assessment of the mental health system in Ethiopia using the World Health Organization- Assessmnet Instrunment for Mental Health System(WHO-AIMS), Addis Ababa, Ethiopia. 2006

30. Ministry of Health of Ethiopia. Federal Democratic Republic of Ethiopia, national mental health strategy 2012/13- 2015/16, Addis Ababa, Ethiopia. 2012.

31. Diamond PMWE, Holzer III CE, Thomas C, des AC. The prevalence of mental illness in prison. Adm Policy Ment Health. 2001;29:21-40.

32. Spitzer RL, Kroenke K, Williams JBW, Löwe B. A brief measure for assessing generalized anxiety disorder, The GAD-7. Arch Inern Med. 2006;166:1092-7.

33. Andrews $G$, Slade T. Interpreting scores on the Kessler Psychological Distress Scale (k10). Aust N Z J Public Health. 2001;25:494-7.

34. Kessler RC, Andrews GC. Short screening scales to monitor population prevalences and trends in non-specific psychological distress. Psychol Med. 2002:32:959-76.

35. Alemi F, Stephens R, Arendt R, Llorens S, Schaffer D, Nemes S. The orientation of social support measure. Research Gate, BubMed. 2002; $876: 1-14$. Article in press 
36. Rich JL, Byrne JM, Curryer C, Byles JE, Loxton D. Prevalence and correlates of depression among Australian women: a systematic literature review, January 1999-January 2010. BMC Research Note. 2013;6(424):1-16.

37. Rabiei MAS, Ghaleiha A, Hosseini SM, Nikooseresht M, Zahirnia M. Depression prevalence and underlying risk factors in the elderly of Hamadan, Iran. Avicenna J Neuro Psych Physio. 2015;2(1):1-4.

38. Comijs HC, Nieuwesteeg J, Kok R, Marwijk HWv, Mast RCvd, Naarding P, et al. The two-year course of late-life depression; results from the Netherlands study of depression in older persons. BMC Psychiatry. 2015; 15(20):1-9.

39. Deribew A, Tamirat YS. How are mental health problems perceived by a community in Agaro town? Ethiop J Health Dev. 2005;19(2):153-9.

40. Mugisha J, Muyinda H, Malamba S, Kinyanda E. Major depressive disorder seven years after the conflict in northern Uganda: burden, risk factors and impact on outcomes (The Wayo-Nero Study). BMC Psychiatry. 2015;15(48): $1-12$.

41. Maske UE, Busch MA, Jacobi F, Beesdo-Baum K, Seiffert I, Wittchen H-U, et al. Current major depressive syndrome measured with the Patient Health Questionnaire-9 (PHQ-9) and the Composite International Diagnostic Interview (CIDI): results from a cross-sectional population-based study of adults in Germany. BMC Psychiatry. 2015;15(77):62-6.

42. Bair MJ, Kroenke K, Sutherland JM, McCoy KD, Harris H, McHorney CA. Effects of depression and pain severity on satisfaction in medical outpatients: analysis of the Medical Outcomes Study. J Rehabil Res Dev. 2007:44(2):143-52.

43. WHO. WHO global health estimates, http://www.who.int/mental_health/ prevention/suicide/suicideprevent/en/. 2000.

44. Larney S, Topp L, Indig D, O'Driscoll C, Greenberg D. A cross-sectional survey of prevalence and correlates of suicidal ideation and suicide attempts among prisoners in New South Wales, Australia. BMC Public Health. 2012;12(14):1-7.

45. Duko B, Gebeyehu A, Ayano G. Prevalence and correlates of depression and anxiety among patients with tuberculosis at WolaitaSodo University Hospital and Sodo Health Center, WolaitaSodo, South Ethiopia, Cross sectional study. BMC Psychiatry. 2015;15(1):214. Epub 2015/09/16.

46. Barger SD, Messerli-Bürgy N, Barth J. Social relationship correlates of major depressive disorder and depressive symptoms in Switzerland: nationally representative cross sectional study. BMC Public Health. 2014;14(273):1-10.

47. Hawkley LC, Cacioppo JT. Loneliness matters: a theoretical and empirical review of consequences and mechanisms. Ann Behav Med. 2010;40:218-27.

48. Hays JC, Landerman LR, George LK, Flint EP, Koenig H, Land K, et al. Social correlates of the dimensions of depression in the elderly. J Gerontol B Psychol Sci. 1998;53:31-9.

49. Roberts RE, Kaplan GA, Shema SJ, Strawbridge WJ. Does growing old increase the risk for depression? Am J Psychiatry. 1997;154:1384-90.

50. Buber I, Engelhardt H. Vienna Institute of Demography Working Papers; The relation between depressive symptoms and age among older Europeans, Findings from SHARE. In: Sciences AAo, editor. Vienna Institute of Demography A-1040 Vienna. AustriaWohllebengasse12-14; 2008.

51. Dhara DR, Jogsan YA. Depression and psychological well-being in old age J Psychology \& Psychotherapy. 2013;3(3):117-20.

52. Beekman ATF, Deeg DJH, Van Tilburg T, Smit JH, Hooijer C, van Tilburg W. Major and minor depression in later life: a study of prevalence and risk factors. J Affect Disord. 1995;36:65-75.

53. Prince MJ, Beekman ATF, Deeg DJH, Fuhrer R, Kivela SL, Lawlor BA, et al. Depression symptoms in late life assessed using the EURO-D scale. $\mathrm{Br} J$ Psychiatry. 1999;174:339-49.

54. Kay DWK, Henderson AS, Scott R, Wilson J, Rickwood D, Grayson DA. The prevalence of dementia and depression among the elderly living in the Hobart community: the effect of the diagnostic criteria on the prevalence rates. Psychol Med. 1985;15:771-88.

55. Kramer M, German PS, Anthony JC, Van Korff M, Skinner EA. Patterns of mental disorders among the elderly residents of Eastern Baltimore. J Am Geriatr Soc. 1985;33:236-45.

\section{Submit your next manuscript to BioMed Central and we will help you at every step:}

- We accept pre-submission inquiries

- Our selector tool helps you to find the most relevant journal

- We provide round the clock customer support

- Convenient online submission

- Thorough peer review

- Inclusion in PubMed and all major indexing services

- Maximum visibility for your research

Submit your manuscript at www.biomedcentral.com/submit
C Biomed Central 